\title{
Reformulação e expansão dos cursos superiores de tecnologia no Brasil: as dificuldades da retomada da educação profissional*
}

口 Adriana Roseli Wünsch Takahashi**

Wilson Aparecido Costa de Amorim***

\section{Resumo}

A discussão sobre a retomada da Educação Profissional no Brasil, enquanto promotora da inserção no mercado de trabalho e da inclusão social, tangencia outros importantes tópicos como o desenvolvimento da Economia Baseada no Conhecimento - EBC e a difusão de um Sistema Nacional de Inovação. Dentro deste panorama, um pilar essencial é composto pelo setor educacional e, dentro dele, pelas universidades e a sua capacidade de criação e transferência de conhecimento para a sociedade como um todo. A tarefa posta para um dos segmentos do nível universitário - a Educação Tecnológica Superior - é o preenchimento ágil e de qualidade de lacunas de mão-de-obra surgidas no mercado de trabalho por conta da chegada e disseminação de novas tecnologias. Com tais considerações, este artigo se propõe a discutir o papel organizador do Estado e as políticas públicas implementadas nos últimos anos para a reformulação e expansão do sistema profissional de educação, em específico nos Cursos Superiores de Tecnologia. Por fim, busca-se oferecer referências para a organização de uma agenda de pesquisas com vistas à melhoria nas políticas públicas voltadas para esta área, bem como de suas formas de avaliação de impacto.

Palavras-chave: Inovação. Economia baseada em conhecimento. Educação profissional. Cursos superiores de tecnologia. Políticas públicas.

\section{Reformulation and expansion of the Higher Technological Courses in Brazil: the difficulties of the professional education retaken. Abstract}

The discussions about the retaken of the professional education in Brazil as the responsible for encouraging the labor market insertion and also the social

\footnotetext{
Uma versão preliminar deste artigo foi apresentado no II EnAPG- Encontro de Administração Pública e Governança, realizado em São Paulo, de 22 a 24 de novembro de 2006. Esta versão contou com o apoio do PROGEP - FIA da FEA USP.

** Doutora em Administração, Universidade de São Paulo (USP); Professora da Universidade Federal do Paraná. E-mail: adrianarwt@terra.com.br

*** Doutor em Administração, USP; Professor da Universidade São Judas Tadeu, SP. E-mail:wilsonamorim@bighost.com.br
} 
inclusions have other important subjects like the development of the Economy Based on Knowledge- EBK and the National Innovation System diffusion. In this point of view, the educational sector is considered an essential base, composed by the Universities and their ability to create and transfer knowledge for the whole society. The duty of the higher technological education, which is one sector of the higher education, is to provide quick and high level quality labor to fill the blanks left by the appearance and dissemination of new technologies. This paper presents the State's organizer role and public politics which have been implemented to reformulate and to expand the professional educational system, especially the Technological Colleges. And it also intends to offer references to organize a scheduled research to improve public politics in this area and its impact evaluation forms.

Keywords: Innovation. Economy based on Knowledge. Professional Education. Higher Technological Courses. Public Politics.

\section{Reformulación y expansión de los cursos superiores de tecnología en Brasil: las dificultades de la retomada de la educación profesional Resumen}

La discusión sobre la retomada de la Educación Profesional en Brasil, como promotora de la inserción en el mercado de trabajo y de la inclusión social, toca otros importantes puntos como el desarrollo de la Economía Basada en el Conocimiento - EBC y la difusión de un Sistema Nacional de Innovación. Dentro de este escenario, un pilar esencial es compuesto por el sector educacional $y$, en este contexto, por las universidades y su capacidad de creación y transferencia de conocimiento para la sociedad como un todo. La tarea puesta para un de los segmentos del nivel universitario - la Educación Tecnológica Superior - es rellenar de modo ágil y con calidad la carencia de trabajadores en el mercado de trabajo causada por la llegada y diseminación de nuevas tecnologías. Con tales consideraciones, este artículo se propone a discutir el papel de organizador del Estado y las políticas públicas implementadas en los últimos años para la reformulación e expansión del sistema profesional de educación, en especifico en los Cursos Superiores de Tecnología. Por fin, se intenta ofrecer referencias para la organización de una agenda de pesquisas para la mejoría de las políticas públicas para esta área, bien como de sus formas de evaluación de impacto.

Palabras clave: Innovación. Economía basada en el conocimiento. Educación profesional. Cursos superiores de tecnología. Políticas públicas.

\section{Introdução}

Segundo autores econômicos neo-schumpeterianos, a esfera pública dos países desenvolvidos possui, entre outras tarefas, a elaboração de políticas públicas voltadas para o estímulo às inovações. As prioridades dessas políticas seriam o incentivo à difusão tecnológica, o incremento do capital humano e a promoção da mudança organizacional (OECD, 1996, p. 19). 
Um destes autores, Lundvall, afirma que uma política voltada à inovação deveria contribuir para a capacidade de aprendizagem das empresas, das instituições voltadas para o conhecimento e das pessoas. Em poucas palavras, para que a inovação aconteça, a aprendizagem deve ser objetivo e meio em todos os lugares, inclusive nas organizações. Desta forma, alguns dos elementos centrais para a aprendizagem seriam o desenvolvimento de recursos humanos, as novas formas de organização empresarial, a formação de redes, a definição de uma nova função dos serviços intensivos em conhecimentos e das universidades (LUNDVALL, 2003, p. 117).

Dentro destas redes, um pilar essencial é composto pelo setor educacional e, dentro dele, pelas universidades e a sua capacidade de criação e transferência de conhecimento para a sociedade como um todo, especialmente na sua dimensão econômica. Em tempos de mercados extremamente dinâmicos, a pesquisa e a formação de recursos humanos são condições centrais para o bom desempenho das empresas e das economias nacionais. A tarefa posta para um dos segmentos do nível universitário - a Educação Tecnológica Superior - é o preenchimento ágil e de qualidade de lacunas de mão-de-obra surgidas no mercado de trabalho por conta da chegada e disseminação de novas tecnologias.

objetivo deste texto é apresentar algumas das principais questões hoje envolvidas com o ensino tecnológico de nível superior no Brasil, dentro deste quadro. Para isto, iremos tratar:

- das características da chamada EBC que hoje demanda cada vez mais o sistema educacional;

- das estatísticas e condições do sistema educacional brasileiro;

- do ensino tecnológico superior no Brasil, suas respectivas políticas públicas e mudanças recentes na legislação;

- das dificuldades de avaliação dos impactos das políticas públicas na área educacional de cunho tecnológico;

- das dificuldades organizacionais das escolas diante destas mudanças (novidades nos marcos regulatórios, concorrência e exigência de novos conteúdos e formatos).

Espera-se ao final deste trabalho, oferecer referências para a organização de uma agenda de pesquisas com vistas à melhoria nas políticas públicas voltadas para esta área, bem como de suas formas de avaliação de impacto.

\section{Economia baseada no conhecimento - EBC: uma nova configuração na sociedade atual}

Educação e conhecimento são termos inseparáveis, inter-relacionados e interdependentes. Atualmente, o conhecimento é disseminado e produzido mais rapidamente do que antes, adquirindo assim uma nova dimensão. $O$ desenvolvimento de áreas como as tecnologias de informação e comunicação, biotecnologia, engenharia de novos materiais, assume papel-chave neste processo (DAHLMAN, 2002; CASTELLS, 1999) caracterizado como 'economia baseada no conhecimento' (OECD, 1996). 
Tal realidade fomentou o debate sobre o conhecimento e suas diversas implicações/aplicações na economia e nas organizações, bem como o debate sobre a relevância da educação nas sociedades. Esta urgência de investimentos em conhecimento nas EBC's tem pressionado significativamente os sistemas educacionais em todos os níveis, posto que eleva a demanda por educação contínua para todos.

Estas mudanças estão refletidas nos trabalhos dos economistas neo-schumpeterianos. Para eles, a sofisticação da divisão do trabalho e a importância crescente da ciência apontam para uma articulação mais complexa do trabalho, identificável em um sistema nacional de inovação. Dentro destes sistemas, a estrutura educacional para manutenção dos fluxos de informação é um pré-requisito. Ou seja, os sistemas de inovação institucionalizam a aplicação sistemática da ciência à produção (PAULA; CERQUEIRA; ALBUQUERQUE, 2000).

Castells (1999) destaca que o processo de globalização é informacional pela relação e dependência que a economia tem com a informação e o conhecimento (GIDDENS, 1999).

Fritz Machlup (apud LENHARI; QUADROS, 2002) - principal precursor do conceito de Economia Baseada no Conhecimento - EBC -, destaca que produção e distribuição de conhecimento passaram a ser uma atividade econômica e da educação. Dahlman (2002, p. 174) aponta a definição de uma EBC como "aquela que estimula suas organizações e pessoas a adquirirem, criarem, disseminarem e usarem o conhecimento de modo mais eficientemente para um maior desenvolvimento econômico e social". De acordo com Foray e Lundvall (1996), as características importantes desta economia residem na dinâmica estabelecida entre conhecimento tácito e decodificado, na crescente importância das redes de conhecimento e, na aceleração dos processos de aprendizagem interativa. Para Lenhari e Quadros (2002), a EBC assume o conhecimento como principal recurso e a capacidade de aprender como o principal processo em um contexto de rápidas mudanças tecnológicas, de mercado, de formatos organizacionais e da capacidade inovativa como condição de competitividade. Os autores destacam que a aquisição de novas habilidades e conhecimento (learnto-learn), se traduz na capacidade de aprender e de transformar o aprendizado em fator competitivo e é fundamental neste processo. Por isso, alguns autores como Foray e Lundvall (1996) assumem a EBC como Economia Baseada no Aprendizado. Desta forma, no cerne da economia do conhecimento estão o volume, a natureza e a direção da produção do conhecimento, sua disseminação e seu uso (BENGTSSON, 2002).

No âmbito macro, a necessidade de maciços investimentos no setor educacional para atingir padrões de competitividade no mercado global tem ampliado a discussão do papel organizador do Estado, para incentivar e estimular o desenvolvimento deste setor ao crescimento econômico e desenvolvimento nacional (TAKAHASHI; CASTOR, 2000). No âmbito micro, as organizações têm experimentado novos padrões de competitividade neste cenário de redes dinâmicas que exigem novos estilos de gerenciamento (DAHLMAN, 2002). As em- 
presas que desenvolvem vantagens competitivas baseadas no conhecimento mantêm mais facilmente a liderança frente aos seus concorrentes (QUINN; ANDERSON; FINKELSTEIN, 2000).

As demandas da sociedade (macro) e as demandas das organizações (micro) salientam a necessidade de investimentos em educação nas EBC's, como forma de atender à demanda por educação contínua para todos. Com isso, a educação e a aprendizagem assumem um papel relevante, levando ao questionamento sobre o seu papel e sua função neste novo contexto (BENGTSSON, 2002). Lenhari e Quadros (2002) salientam que conhecer a base de recursos de um país por meio da sua força de trabalho ocupada pode ser um bom indicador para conhecer sua posição na EBC. Desta forma, observa-se o papel fundamental da educação para a força de trabalho, cujas qualificações são aproveitadas no interior do processo produtivo das EBCs.

\section{O papel da educação na economia do conhecimento: a interface entre conhecimento e educação}

No Brasil, os estudos sobre o sistema educacional e a gestão escolar, constituem um campo carente de pesquisas, uma área negligenciada, permeada pelos debates ideológicos conflitantes com os estudos gerenciais (TAKAHASHI, 2001). A competitividade do mercado, que também se estendeu ao setor educacional, associada ao nível de turbulência ambiental, demanda novos estudos para eliminar as carências deste setor.

Fleury e Fleury (2004, p. 122) destacam a importância da educação no desenvolvimento econômico de um país. Os autores analisam empresas transnacionais e empresas brasileiras, e salientam que "a atratividade do país seria maior se, além dos incentivos econômico-financeiros, houvesse maiores investimentos educacionais, disponibilizando no mercado pessoas mais qualificadas, melhoria na infra-estrutura e a reforma tributária". Dahlman (2002) indica que o Brasil necessita desenvolver uma estratégia coerente para aproveitar as oportunidades da economia do conhecimento e minimizar os riscos que ela traz, precisa ainda atentar para os gastos com educação de modo eficiente, que é a base para criar, adquirir, adaptar, disseminar, compartilhar e usar o conhecimento, não somente em cursos acadêmicos e bacharelados, mas também em cursos profissionalizantes voltados para atender as necessidades do mundo da produção e do trabalho (CASTRO, 2002; LENHARI; QUADROS, 2002).

Bengtsson (2002) elenca seis questões indispensáveis na agenda das políticas brasileiras para o ingresso mais ativo na economia do conhecimento: inclusão do jovem no sistema educacional, mudança da cultura educacional baseada nos valores da velha economia, alfabetização dos adultos, incremento das parcerias entre o público e o privado, reforma educacional baseada em aprendizagem constante ao longo da vida e o desenvolvimento de uma cultura de aprendizagem.

Uma pesquisa do Banco Mundial auxilia a contextualização do Brasil na EBC ao avaliar a posição de alguns países na economia do conhecimento com base em quatro pilares (que consolidam 70 indicadores estruturais e qualitativos) - regime de incentivos econômicos, inovação, infra-estrutura de informação, e educação. A pes- 
quisa, mostrou que a partir de 1995, o Brasil melhorou na infra-estrutura de informação e nos incentivos econômicos. Em inovação, apesar de algumas áreas de significativa força tecnológica, seu desempenho foi fraco: houve uma melhora na produção científica, mas não houve melhora quanto ao uso do conhecimento global, medido pela variável de comércio. Em educação, o Brasil apresentou melhora nas matrículas secundárias, mas não em letramento ou educação terciária.

Para Dahlman (2002), a educação é o 'calcanhar de Aquiles' para que o Brasil esteja pronto para a economia do conhecimento, pois uma baixa taxa de educação profissional e superior implica baixo percentual de trabalhos técnicos e profissionais. Algumas estatísticas evidenciam as condições do sistema educacional brasileiro. Em 2000, o período médio de escolarização era de apenas 4,9 anos no Brasil, enquanto era de 8,8 na Argentina, 7,5 no Chile, 9,4 na Irlanda, 10,0 na Finlândia e 10,8 na Coréia do Sul (países de significativo crescimento econômico nos últimos anos). Considerando a população de 18 a 24 anos no Brasil, o número de matrículas no ensino superior corresponde a apenas $15 \%$ e no ensino médio não ultrapassa 33\% (CASTRO, 2002). Em 1999 apenas 6,7\% do total de ocupados no Brasil possuíam curso superior completo. Entre 1989 e 1999, no setor industrial, a participação do número de ocupados com curso superior aumentou apenas de $3,9 \%$ para $5,2 \%$, enquanto, por outro lado, a indústria eliminou $48,1 \%$ dos trabalhadores com escolaridade até o ensino fundamental (antigo $1^{\circ}$. Grau) incompleto (LENHARI; QUADROS, 2002).

Mediante este cenário, apesar das muitas iniciativas do segmento empresarial na busca e promoção da aprendizagem e na difusão do conhecimento, o governo tem um importante papel na sua efetividade, seja por meio de treinamento formal ou de esforços por consórcio de firmas para desenvolver técnicas de produção de aprendizagem intensiva. A necessidade de transformação dos métodos de produção e de modelos organizacionais requer uma aprendizagem mais rápida e contínua por parte dos indivíduos. Esta necessidade contrasta com a instabilidade do emprego, que, por sua vez, implica menos incentivo por parte das organizações para investir em treinamento. $\bigcirc$ governo pode auxiliar a resolver este dilema ajudando a desenvolver métodos de aprendizagem para os empregados, garantindo que estudantes tenham oportunidade de praticar a aprendizagem por meio do trabalho. Uma das medidas tomadas em diversos países é a reformulação da educação profissional de forma combinada com a educação acadêmica, o que reflete a convergência do trabalho e da aprendizagem no local de trabalho (STERN, 1996). Segundo Souza (2005, p. 14), a

educação profissional na Sociedade do Conhecimento precisa ser flexível para permitir a introdução de estruturas modulares no currículo, de sorte a permitir e facilitar freqüentes idas e vindas entre o mercado de trabalho e o sistema de educação profissional e a atualização técnica e profissional dos trabalhadores.

Além disso, "o sistema de educação profissional precisa estar profundamente vinculado ao mercado de trabalho e à evolução tecnológica" (SOUZA, 2005, p. 4). 
Em consonância com as tendências internacionais, sintetizadas a seguir, o Brasil tem adotado, por meio do Ministério da Educação, estratégias de política educacional nos diversos níveis de ensino, em particular na educação profissional.

\section{A reformulação da educação profissional no Brasil}

A educação profissional e o treinamento profissional desenvolveram-se nas cidades industriais como em Manchester, na Inglaterra, em 1824, considerada por muitos a primeira universidade tecnológica (Universidade de Manchester, Instituto de Ciência e Tecnologia - UMIST); em Barcelona, na Espanha, em 1851 (Escola de Engenharia Industrial de Barcelona); e nos Estados Unidos, em 1865 (Instituto de Tecnologia de Massachussets - MIT). No século seguinte, tal demanda intensificou-se e resultou no surgimento de outras instituições como as Universidades de Tecnologia na França, em 1972, iniciada por Compiègne, e as Fachhochschules (FHs) na Alemanha no mesmo ano. Na América Latina, foi implantada a Universidade Tecnológica Nacional na Argentina, em 1959, e os Centros Federais de Educação Tecnológica (CEFETs) no Brasil, em 1978.

Stern (1996) cita diversos exemplos de países que têm realizado reformas na educação profissional. Nos Estados Unidos houve uma proliferação de novos programas delineados para integrar a educação acadêmica e profissional, como por exemplo, o teach prep, que combina o currículo acadêmico e profissional e também liga os dois últimos anos do secondary school com os dois primeiros anos do post-secondary educational. O School-to-Work Opportunities Act, em 1994, forneceu recursos federais para os estados desenvolverem e implementarem novos sistemas de escola para o trabalho, sendo a aprendizagem baseada no trabalho uma componente necessária.

O Japão desenvolveu um novo currículo integrado acadêmico-profissional para a high school, que até 1994 oferecia somente um currículo geral como preparação para a universidade ou um currículo profissional especializado. A França tem criado uma variedade de diplomas chamados secundário-superior: geral, técnico e profissional. A partir de 1985, o país inseriu o diploma profissional, oferecendo a opção de receber um diploma secundário-superior após um adicional de dois anos aos graduados de programas profissionais de dois anos. Na Alemanha, um sistema duplo de aprendizagem tem sido amplamente aceito como um modelo de sucesso para iniciar a educação profissional. A Suécia requer que estudantes do novo programa secundário superior de três anos passem 15\% do seu tempo em locais de trabalho. A Austrália estava criando o "student traineeships" para permitir que estudantes combinem os estudos da escola com a experiência do trabalho e o treinamento fora do local de trabalho. A Coréia reestruturou seu currículo de high school profissional para incluir um ano em empresas nos programas de três anos (STERN, 1996). A Nova Zelândia possui um programa de cursos de graduação de curta duração focados na parte prática, ofertados pelas escolas politécnicas e institutos de tecnologia, que variam de um a três anos. Estes cursos são semelhantes aos ofertados pelas Faculdades de Tecnologia do Brasil, com treinamento profissional e formação específica (CURTA duração é opção ..., 2004). 
Reino Unido introduziu uma série de modificações no seu sistema educacional nos últimos anos a fim de equalizar o percurso acadêmico e profissional. Uma delas foi a criação de rotas alternativas para a educação de nível superior, baseada em habilidades e competências voltadas para a prática profissional no mercado de trabalho. Estes cursos, que provêem uma qualificação de nível superior, podem ser de um ano (Higher National Certificate - HNC) ou de dois anos (Higher National Diploma - HND) e possibilitam que o estudante ingresse no $2^{\circ}$. ou $3^{\circ}$. ano de um curso de bacharelado. Outra mudança foi a criação dos foundation degrees, que também são qualificações de ensino de nível superior voltadas para competências e habilidades do mercado de trabalho em diversas áreas. Estes cursos, assim como os HND's, apresentam mais 1.100 opções, estão num nível intermediário dentro da estrutura de ensino de nível superior (que vai até o bacharelado com 360 créditos), e são compostos de 240 créditos. Os cursos profissionalizantes são ofertados pelos colleges, chamados de Colleges of Further and Higher Education. Estes tipos de cursos assemelham-se aos cursos tecnológicos do Brasil. Henriques (1999) observa que Inglaterra, França, Alemanha e Estados Unidos foram os países que mais influenciaram a educação profissional no Brasil.

Na Europa como um todo, ocorreram mudanças nos últimos anos. Em 1999, ministros da educação de 29 países reuniram-se na ltália e assinaram a Declaração de Bolonha, incluindo o sistema de formação em módulos ou ciclos semelhante ao sistema americano de colleges.

De acordo com este documento, cada país comprometeu-se com o estudo de um sistema de dois ciclos: pré-graduado ou curto, numa preparação para o mercado de trabalho, e formação graduada ou longa, dependente da conclusão do primeiro. Esta estrutura visa a garantir a verticalidade e o foco, com flexibilidade (ZONTA, 2005).

No Brasil, em 2005, um seminário, promovido pelos ministérios da Educação e do Trabalho, reuniu representantes da Europa e América Latina para trocar experiências e colher subsídios para a elaboração de uma proposta do governo federal de criação de um Sistema Nacional de Certificação Profissional (SNPC). A certificação profissional é o reconhecimento formal dos conhecimentos e práticas do trabalhador desenvolvidos durante a vida, no trabalho, na escola ou em programas formais de qualificação social e profissional.

Além dos reflexos de um panorama mundial, a situação interna do sistema educacional brasileiro também pressionou para a ampliação da oferta de vagas de cursos pós-médio e superior no Brasil. Entre 1994 e 2002, houve um crescimento de $71 \%$ no ensino médio e, em 2001, 1,85 milhão de pessoas concluíram o ensino médio, mais do que o dobro do número em 1994 (CASTRO, 2002). A estratégia governamental de fomentar a educação profissional e os cursos tecnológicos não constituiu uma novidade em si quanto à criação de uma nova modalidade, mas sim quanto à reorganização, reformulação e expansão destes cursos.

Os cursos tecnológicos, apesar de existirem há mais de 30 anos, ganharam nova dimensão neste cenário, principalmente a partir de sua reformulação na Lei de Dire- 
trizes e Bases - LDB (BRASIL, 1996), e no Decreto Federal n. 2.208 (BRASIL, 1997a). Em 2001, os primeiros centros mantidos pela iniciativa privada foram credenciados para ofertar Cursos Superiores de Tecnologia - CSTs, regulamentados pela Secretaria de Educação Profissional e Tecnológica - SETEC, do Ministério da Educação - MEC. A organização e o incentivo desta modalidade educacional trouxe uma nova perspectiva de formação superior para o Brasil que já existe em outros países (CONSELHO NACIONAL DE EDUCAÇÃO, 2001). Desde então, seu crescimento tem sido significativo no âmbito privado e público. Tendo em vista o tempo em que está em funcionamento e a tendência de expansão, é justamente neste momento que se faz necessário avaliar as políticas públicas a fim de confrontar os resultados atuais com seus propósitos de implementação. Muitas vezes, as políticas públicas carecem de mecanismos de avaliação efetivos para averiguar a adequação entre meios e fins, sendo decisiva para o sucesso da formulação e do planejamento. Abranches (1989, p. 27) aponta que seria no mínimo prudente estabelecer um programa de acompanhamento e avaliação das áreas sociais mais importantes para promover correções, com base em informação e evidência confiáveis, a fim de pelo menos minimizar, ou até mesmo eliminar, efeitos colaterais socialmente perversos.

\section{A educação profissional de nível tecnológico no Brasil}

Historicamente, no Brasil, o termo educação tecnológica começou a ser usado na década de 70, porém manteve ao longo do tempo a influência histórica que marcou o preconceito à educação profissional, sempre associada à formação profissional de classes menos favorecidas. Esse preconceito começou a ser mitigado somente nos últimos anos por meio da Constituição Federal de 1988 (BRASIL, 1998) e da nova LDB (BRASIL, 1996), conhecida também pelo nome de seu idealizador - Lei Darcy Ribeiro. Esta lei determina que a educação profissional integre-se às diferentes formas de educação (CONSELHO NACIONAL DE EDUCAÇÃO, 2002).

Os Cursos Superiores de Tecnologia - CST's - originaram-se das necessidades do mercado nos anos 60, e foram respaldados pela Lei n. 4024 (BRASIL, 1961), a primeira LDB. Em seu Artigo 104, a LDB contemplava "a organização de cursos ou escolas experimentais, com currículos, métodos e períodos escolares próprios". A reforma universitária implantada pela Lei Federal n. 5.540 (BRASIL, 1968) propôs a instalação e o funcionamento de "cursos profissionais de curta duração, destinados a proporcionar habilitações intermediárias de grau superior", a serem ministrados em universidades ou estabelecimentos de educação superior. Esta lei não explicitou a possibilidade de os cursos serem ofertados por centros criados especialmente para esse fim, mas nos seus Artigos 18 e 23, mencionou a possibilidade de implantação de faculdades e de cursos de tecnologia que ofertassem cursos profissionais com duração e modalidades diferentes para atender a realidades diversas do mercado de trabalho (CONSELHO NACIONAL DE EDUCAÇÃO, 2002). Assim, surgiram os primeiros centros de educação tecnológica no Brasil.

A discussão sobre uma nova lei de diretrizes e bases da educação nacional durou quase oito anos, resultando em lei em dezembro de 1996. A LDB (BRASIL, 1996) 
possui 92 artigos, e quatro deles tratam da educação profissional (artigos 39 a 42). Contudo, ela não explicita a modalidade dos cursos tecnológicos.

Outras alterações foram feitas para caracterizar a Educação Profissional, como o Decreto $n^{\circ}$. 2.208, de 17 de abril de 1997 (BRASIL, 1997a), que regulamentou os artigos 39 a 42, especificando e reorganizando a educação profissional. Com a LDB e este Decreto, o ensino tecnológico ganhou nova dimensão e reiniciou sua trajetória no ensino brasileiro (ANET, 2003). O nível profissional foi separado do ensino médio, passando cada um a ter seu próprio currículo (HENRIQUES, 1999). Os programas profissionais passaram a ser ofertados em paralelo ou de forma seqüencial, mas não mais em programas combinados como anteriormente. $\bigcirc$ mesmo Decreto distinguiu três níveis no ensino profissional: básico, técnico e tecnológico (correspondente a cursos de nível superior na área tecnológica, destinados a egressos do ensino médio e técnico).

Após a publicação do Decreto n². 2.208 (BRASIL, 1997a), houve ainda a publicação de uma série de instrumentos normativos que caracterizou a reforma da Educação Profissional: Portaria MEC n . 646/97 (BRASIL, 1997c), Portaria/MEC nº 1.005/ 97 (BRASIL, 1997b), Portaria MEC/MTb nº 1.018/97 (BRASIL, 1997d) e Lei Federal $\mathrm{n}^{\circ}$. 9.649 (BRASIL, 1998). A organização e incentivo desta modalidade educacional pela SETEC trouxe uma nova perspectiva de formação superior para o Brasil, já existente em outros países. Nos Estados Unidos e em alguns países da Europa, ela abrange metade dos alunos do ensino superior, e menos de 5\% no Brasil.

Em 2001, o Parecer CNE/CES 436 (CONSELHO NACIONAL DE EDUCAÇÃO, 2001) discutiu e analisou os Cursos Superiores de Tecnologia, definindo-os como cursos de graduação com características especiais, distintos dos tradicionais. Segundo o Parecer, todos os cursos de nível tecnológico são cursos de graduação, e seus concluintes ficam aptos a prosseguir seus estudos em nível de pós-graduação. Por isso, estão enquadrados no disposto no Inciso II do Artigo 44 da LDB, que regulamenta o ensino superior no Brasil.

Em 2002, as Diretrizes Curriculares Nacionais Gerais para a Educação Profissional de Nível Tecnológico foram definidas pelo Parecer CNE/CP 29 (CONSELHO NACIONAL DE EDUCAÇÃO, 2002) e proposta de resolução anexa. Além de definir os critérios e objetivos da educação tecnológica, as Diretrizes também constituíram um esforço de romper com o preconceito histórico nacional de que a educação para o trabalho destina-se à formação profissional de classes sociais menos favorecidas, ofertando uma educação profissional de nível superior fundamentada no desenvolvimento do conhecimento tecnológico e na realidade do mundo do trabalho. Esta resolução, fundamentada no Parecer CNE/CES 436/2001 (CONSELHO NACIONAL DE EDUCAÇÃO, 2001) e no Parecer CNE/CP 29/2002 (CONSELHO NACIONAL DE EDUCAÇÃO, 2002), define, em seu Art. $1^{\circ}$, que

a educação profissional de nível tecnológico, integrada às diferentes formas de educação, ao trabalho, à ciência e à tecnologia, objetiva garantir aos cidadãos o direito à aquisição de competências profissionais que os tornem aptos para a inserção em setores profissionais nos quais haja utilização de tecnologias. 
Neste âmbito, entende-se por competência profissional "a capacidade pessoal de mobilizar, articular e colocar em ação conhecimentos, habilidades, atitudes e valores necessários para o desempenho eficiente e eficaz de atividades requeridas pela natureza do trabalho e pelo desenvolvimento tecnológico" (CONSELHO NACIONAL DE EDUCAÇÃO, 2002, Art. $7^{\circ}$ ). Estas competências acompanham o diploma do curso e são definidas no perfil profissional do mesmo.

A partir de 2004, a educação profissional em vigor no Brasil, segundo o Decreto $n^{\circ} .2 .208 / 97$ (BRASIL, 1997a), reformada pelo Decreto $n^{\circ} .5 .154$, de 23 de julho de 2004 (BRASIL, 2004a), passou a consistir nos três níveis:

"I - formação inicial e continuada de trabalhadores;

II - educação profissional técnica de nível médio; e

III - educação profissional tecnológica de graduação e de pós-graduação".

primeiro nível, formação inicial e continuada de trabalhadores, refere-se à capacitação, aperfeiçoamento, especialização e atualização em todos os níveis de escolaridade, é articulada preferencialmente com os cursos de educação de jovens e adultos, e objetiva a elevação do nível de escolaridade do trabalhador. O segundo, educação profissional técnica de nível médio, pode ser ofertada integrada com o ensino médio, concomitante ou subseqüente. Dentre as três modalidades do ensino profissional, a terceira, de educação profissional tecnológica de graduação e de pós-graduação, assume um caráter específico e próprio. Esta modalidade visa à qualificação e requalificação de acordo com novas necessidades do mercado de trabalho, e é suportada pelo surgimento das novas tecnologias, exigidas pela globalização econômica que demanda do trabalhador novas competências e habilidades.

Assim, a educação profissional e tecnológica começou a consolidar-se como um esforço estratégico do Ministério da Educação visando às mudanças no mundo do trabalho, na conomia nacional e internacional, e nos sistemas sociais: "cursos superiores de tecnologia [...] uma das principais respostas do setor educacional às necessidades e demandas da sociedade brasileira" (CONSELHO NACIONAL DE EDUCAÇÃO, 2001).

A principal diferença entre os cursos de graduação tecnológicos (que conferem - Diploma de Tecnólogo) e os cursos de ensino superior (que conferem o Diploma de Licenciatura ou Bacharel) está na proposta do primeiro. Os cursos tecnológicos vêm atender a uma demanda do mercado por especialistas dentro de uma área de conhecimento, em vez dos generalistas formados pelas outras modalidades de ensino superior. Os principais atributos da Educação Tecnológica são o foco, a rapidez, a inserção no mercado de trabalho e a metodologia. O foco desta modalidade é a formação em um campo de trabalho definido, alinhado às necessidades atuais. A rapidez refere-se à oferta do curso com uma carga horária menor, de dois ou três anos. Por estarem pautados em pesquisas de mercados para sua oferta e funcionamento, visam à rápida inserção do aluno no mercado de trabalho de acordo com as tendências do mercado. 
A metodologia praticada abrange técnicas, métodos e estratégias focadas na aprendizagem, no saber e no saber-fazer, com propostas didático-pedagógicas voltadas para a prática. Por isso, os cursos tecnológicos não constituem cursos permanentes, mas sim cursos que devem ser continuamente revistos, redesenhados e reorganizados, para garantir a adequação à mutabilidade das necessidades do mercado de trabalho (ANET, 2003). Os currículos dos CST's devem ter flexibilidade, interdisciplinaridade, contextualização e atualização permanente.

Acompanhando o ritmo das mudanças legais, o crescimento dos cursos tecnológicos tornou-se exponencial. O Instituto Nacional de Estudos e Pesquisas Educacionais Anísio Teixeira - INEP, registrou um crescimento de 74\% entre 2000 e 2002 (de 364 para 636), enquanto os cursos de graduação tradicionais aumentaram no mesmo período 36\% (ANET, 2003). Em 2003, de acordo com o Censo INEP (2004), 70,5\% dos alunos continuavam na rede privada, ou seja, a rede privada afirmou-se como responsável por 70\% da oferta dos CST's. Em 2004, o Ministério da Educação autorizou a abertura de mais 501 cursos desta modalidade e reconheceu outros 133, o que significou que as autorizações para estes cursos quadruplicaram no Brasil, sem contar os cursos ofertados por universidades, centros universitários e centros federais de educação tecnológica que não necessitam de autorização do MEC (CURSOS tecnológicos..., 2005). Na rede pública, a oferta de cursos de tecnologia cresceu 93,3\% entre 2003 e 2004 . Um outro exemplo da rápida expansão destes cursos pode ser dado pela análise do crescimento dos CST's em Faculdades e Centros Tecnológicosł.

Nestas instituições, em 1999, eram ofertados 74 cursos, enquanto em 2004 esse número mudou para 758, significando um aumento de dez vezes (INEP, 2004). Para regulamentar a oferta destes cursos, o MEC desenvolveu mecanismos de credenciamento das instituições ofertantes, de autorização de funcionamento de cursos e de reconhecimento e pós-reconhecimento dos mesmos. Para isto, conta com especialistas, capacitados pelo próprio Ministério, para realizar visitas in loco e emitir pareceres consultivos com base em formulários pré-definidos e critérios quantitativos e qualitativos.

A sociedade brasileira reagiu às informações obtidas com a avaliação das instituições de ensino superior. Segundo as estatísticas do Ministério da Educação, a demanda por cursos privados no ensino superior, medida pela relação candidato/vaga, com conceitos A e B, cresceu 41\% entre 1997 e 2002, enquanto diminuiu 18\% por cursos com conceitos D e E. Assim, o processo de avaliação adquire legitimidade na sociedade: "isso demonstra que a difusão de informação produz uma reação da sociedade que tem uma força muito maior que eventuais punições administrativas" (SOUZA, 2005, p. 166). Portanto, a redução nos inscritos nos processos seletivos para as instituições mal avaliadas demonstra que os jovens incorporaram o resultado da avaliação nas suas decisões sobre as instituições que buscavam freqüentar". Além disso, "os empregadores também passaram a olhar o resultado do exame como um indicador das faculdades onde deveriam buscar profissionais para contratar" (SOUZA, 2005, p. 207).

sistema de avaliação vigente está atualmente em fase de mudança. A Lei $\mathrm{n}^{\circ}$. 10.861, de abril de 2004 (BRASIL, 2004c), criou o Sistema Nacional de Avaliação da Educação Superior - SINAES, como novo instrumento de avaliação do INEP. De acor- 
do com a Portaria MEC n. 2.051, de 09 de julho de 2004 (BRASIL, 2004d), que regulamenta a lei acima citada, o SINAES "promoverá a avaliação das instituições de educação superior, de cursos de graduação e de desempenho acadêmico de seus estudantes sob a coordenação e supervisão da Comissão Nacional de Avaliação da Educação Superior (CONAES)", cuja operacionalização é de responsabilidade do INEP.

\section{As políticas públicas da reformulação da educação profissional na modalidade do ensino tecnológico}

O sistema educacional brasileiro passou por várias mudanças a partir de 1990 e significativas reformas a partir de 1995. Esta reestruturação começou "muito lentamente e com grande retardo" (CASTRO, 2003, p. 63). Contudo, inovações importantes foram feitas: informatização dos dados escolares por meio do Censo da Educação, avaliação da educação por meio do Provão e análise das condições de ensino por meio das comissões especialistas de cada área acadêmica (SOUZA, 2005).

A política de estímulo à expansão no ensino superior não ocorreu somente com base nas tendências observadas, mas também a partir do entendimento de que o crescimento explosivo do ensino médio e do ensino de jovens e adultos provocaria aumento da pressão social por mais vagas na educação superior e por alternativas além do tradicional bacharelado (SOUZA, 2005). Tal expansão deixou um desafio para as próximas décadas de proteger a qualidade do ensino (CASTRO, 2003).

A discussão da reforma dos cursos profissionalizantes de nível superior trouxe à tona uma questão espinhosa e altamente ideológica: a decisão de oferecer cursos fortemente fundamentados na academia e/ou cursos mais focalizados no perfil do aluno e aplicados. Seguindo tendências internacionais de fortalecimento da educação profissional, o governo buscou articular a academia à prática por meio dos cursos superiores de tecnologia. Segundo Castro (2003, p. 158): "é difícil imaginar que o Brasil vá ser diferente de todos os outros países do mundo. Portanto, é razoável supor que esse é o nível que vai crescer mais rapidamente nos próximos anos. Tudo indica que há uma demanda reprimida por mais cursos curtos, seja de uma semana, seja de dois anos". Como conseqüência, as escolas especializam-se ao definir um ramo cada vez mais estreito, o que leva a um grau de interação cada vez maior com o setor produtivo: "o Brasil é o único país latino-americano que faz desse modelo uma política deliberada, mostrando pioneirismo na difusão de um estilo muito mais eficiente e funcional de organização de ensino técnico-vocacional" (CASTRO, 2003). Um exemplo deste processo é o que está acontecendo nos Centros Federais de Educação Tecnológica - CEFET's, no Serviço Nacional de Aprendizagem Industrial - SENAl e no Serviço Nacional de Aprendizagem Comercial - SENAC.

A LDB (BRASIL, 1996) e as regulamentações posteriores consolidaram a modalidade de cursos de formação de tecnólogos como uma modalidade de nível superior para a educação profissional (SOUZA, 2005). $\bigcirc$ processo de expansão dos cursos tecnológicos foi acompanhado de uma reestruturação interna do MEC, que se reor- 
ganizou em janeiro de 1990 com a criação da Secretaria Nacional de Educação Tecnológica - SENETE e sua alteração em 1992 para Secretaria de Educação Média e Tecnológica - SEMTEC. Em dezembro de 1999, o MEC emitiu a Portaria nº 1.647 (BRASIL, 1999), que transferiu a supervisão dos CST's da SESU para a SEMTEC. Com o Decreto n’. 5.159 (BRASIL, 2004b), a SEMTEC passou a ser denominada Secretaria de Educação Profissional e Tecnológica - SETEC. A definição das políticas do ensino médio passou, com a nova estrutura, a ser de competência da Secretaria de Educação Básica, ficando a SETEC responsável pela educação profissional. A missão da SETEC consiste em expandir a educação profissional de maneira a atender às necessidades de formação do trabalhador e ampliar o acesso às novas tecnologias. A estrutura organizacional do MEC é composta pelos órgãos da Administração Direta e da Administração Indireta, estando a SETEC na Administração Direta, e as Instituições de Ensino Federal na Administração Indireta.

Para viabilizar as competências da SETEC, foi criado o Fórum Nacional de Educação Profissional e Tecnológica (BRASIL, 2003), de caráter consultivo e vinculado ao MEC. Integrando membros dos diversos ministérios e órgãos afins, este fórum teve por objetivo contribuir para a integração e articulação da educação profissional e tecnológica, sugerir medidas referentes às bases do subsistema, contribuir para a formulação de políticas e instrumentos normativos, propor políticas de formação para os profissionais desta modalidade, propor mecanismos de financiamento, sugerir medidas de integração das instituições ofertantes com a sociedade, propor estudos e pesquisas necessárias ao setor, acompanhar e monitorar a implantação de alterações e opinar sobre assuntos de sua especialidade. Neste fórum a SETEC anunciou seu compromisso para a definição da Política Pública de Educação Profissional e Tecnológica mediante as seguintes ações: a) outra Educação Profissional e Tecnológica - reordenamento legal; b) fortalecimento das redes federais e estaduais de Educação Profissional e Tecnológica e valorização do Educador e do Educando; c) Política de Financiamento, Modernização e Expansão; d) subsistema de Educação Profissional e Tecnológica, que articule as múltiplas redes existentes; e) parceria público-privada.

Em dezembro de 2003, a SETEC iniciou uma discussão sobre a educação tecnológica junto a vários segmentos envolvidos, para elaborar uma proposta de políticas públicas para o setor (BRASIL, 2003b). A finalidade dessas políticas públicas seria embasar a elaboração de uma proposta de Lei Orgânica que fundamentasse esta modalidade da educação nacional. Neste contexto, a SETEC buscou viabilizar um pacto pela valorização da Educação Profissional e Tecnológica, por meio de sua articulação com Conselhos de Dirigentes e Sindicatos dos Setores Educacionais públicos e privados. A intenção era o estabelecimento de uma Política Pública de Educação Profissional e Tecnológica, dentro de uma perspectiva de Profissionalização Sustentável. Essa Proposta de Agenda Mínima Pactuada foi estabelecida entre SETEC, Conselho de Diretores dos CEFET's - CONCEFET, Conselho dos Diretores das Escolas Agrotécnicas Federais - CONDAF, Conselho dos Diretores das Escolas Técnicas vinculadas as Universidades Federais - CONDETUF, e Sindicato Nacional dos Servidores Federais da Educação Básica e Profissional SINASEFE (BRASIL, 2003a). 
Em abril de 2004, a SETEC publicou o documento "Políticas Públicas para a Educação Profissional e Tecnológica" (BRASIL, 2004e)' reafirmando o papel estratégico desta modalidade dentro de sua política econômica nacional. Neste documento, o sistema educacional é definido como historicamente localizado e circunstanciado, e nele circulam movimentos de construção e reconstrução, determinados por fatores de ordem econômico-social e políitico-cultural. Com isto,

o objetivo maior deste documento é o de estabelecer diretrizes e definir políticas públicas para a educação profissional e tecnológica visando à consolidação de ações efetivas que redundem no aperfeiçoamento da democracia, na melhor qualificação do cidadão, jovem ou trabalhador, na redução das desigualdades sociais e na sua participação como agente de transformação para construir o desenvolvimento do Brasil (BRASIL, 2004e).

De acordo com o documento "Políticas Públicas para a Educação Profissional e Tecnológica" (BRASIL, 2004e), os pressupostos que irão alicerçar a compreensão e as práticas da educação profissional e tecnológica são: a) articular a educação profissional e tecnológica com a educação básica; b) integrar a educação profissional e tecnológica ao mundo do trabalho; c) promover a interação da educação profissional e tecnológica com outras políticas públicas; d) recuperar o poder normativo da LDB, Arts. 22, 35 e 36, 39 a 42 (BRASIL, 2004e); e) proceder à reestruturação do sistema público de ensino médio técnico e da educação profissional e tecnológica; e f) comprometer-se com a formação e valorização dos profissionais de educação profissional e tecnológica". Nesse sentido, o documento busca uma inter-relação da educação profissional e tecnológica com outros sistemas sociais, considerando também o sistema econômico, como pode ser observado na intenção do documento: "a questão não é acadêmica. É política. Diz respeito às finalidades estratégicas. Os que interrogam esta modernização econômica esquecem-se, via de regra, de questionar esta modernização do ponto de vista do desenvolvimento social, no sentido mais amplo do conceito. E é da perspectiva deste desenvolvimento que devemos considerar e intervir no sistema educativo". Assim, esta modalidade de ensino assume importância estratégica no desenvolvimento do país e na orientação das ações promovidas pelo MEC (BRASIL, 2004e).

\section{Questões presentes e futuras}

Um sinal de amadurecimento das EBC's nacionais é a montagem e o bom funcionamento do que os autores neo-schumpeterianos qualificam como um Sistema Nacional de Inovação - SNI. O SNI seria composto pelos fluxos e relações existentes entre empresas, indústria, governo e academia no desenvolvimento da ciência e tecnologia e que influenciam empresas e economias que - sob as condicionantes da

\footnotetext{
1 Este quadro de princípios orientadores, apresentado neste documento que tem com objetivo estabelecer diretrizes e definir políticas públicas para a educação profissional e tecnológica, resultou do Documento-Base e do Relatório Final do Seminário Nacional de Educação Profissional: concepções, experiências, problemas e propostas (2003a, 2003b), promovido pela SEMTEC e realizado em Brasília, em junho de 2003, evento que reuniu mais de mil profissionais vinculados às instituições e/ou a atividades ligadas à educação profissional e tecnológica, além de representantes dos sindicatos e do governo.
} 
concorrência/competição - buscariam através do aprendizado contínuo e interativo a inovação em um processo permanente (OECD,1996).

O setor educacional é parte deste sistema, e garante através da pesquisa, extensão e formação, o abastecimento de conhecimento e recursos humanos necessários ao seu funcionamento. No Brasil, a avaliação do sistema educacional tem com ponto de partida baixos indicadores de anos de estudo ou de simples qualificação formal da população. Nos últimos anos, o País tem buscado através de várias mudanças regulatórias e legais eliminar rapidamente esta defasagem, já que não há exemplos de países que tenham ingressado na categoria de EBC ou simplesmente no grupo dos países mais desenvolvidos sem pesquisa e uma população com nível educacional mais elevado.

A educação tecnológica de nível superior integra esta busca através da abertura de possibilidades de formação de um contingente de trabalhadores dentro das caracaterísticas de seus cursos - flexibilidade, contextualidade e interdisciplinaridade. Seria esta a inserção das Instituições de Ensino Superior - IES no âmbito de um Sistema Nacional de Inovação. Entretanto, as dificuldades para que isto aconteça são várias.

\section{As dificuldades de integração das IES ao SNI nacional}

O Brasil possui uma estrutura de ensino tecnológico - na forma de suas CEFET's e outras escolas - tradicional e bem reconhecida no nível secundário. Já a educação tecnológica de nível superior é, em si própria, uma inovação recente na estrutura educacional brasileira. Desta forma, identifica-se um lugar para a existência de cursos desta natureza mas ainda é difícil verificar e avaliar como os egressos destes cursos vêm sendo aceitos no mercado de trabalho. Trata-se de verificar se existe uma conexão entre o pólo demandante de mão-de-obra tecnológica de nível superior no mercado de trabalho e se esta conexão é boa. Dentro desta conexão, é necessário ainda avaliar tanto quantitativa - ou seja, quantos alunos têm sido aproveitados no mercado de trabalho - quanto qualitativamente, ou seja, se uma vez aproveitados, se mostraram adequados às exigências dos postos de trabalho ocupados. Um ponto-chave nesta integração é a detecção das competências profissionais demandadas no mercado e como elas podem ser desenvolvidas no âmbito dos cursos oferecidos pelas IES.

\section{As tensões entre inovar e regular}

Ocompanhamento de todas as mudanças experimentadas pelas IES permite inferir que estas funcionam sob uma forte tensão entre a inovação e a regulação. Por um lado, foi aberto um campo para oferta de novos cursos, com novos formatos e duração, novas tecnologias como as permitidas pela educação à distância e novos conteúdos. Por outro, e na mesma proporção de intensidade, há a preocupação com a regulação deste novo campo que se identifica através das seguidas alterações dos marcos legais destes cursos na busca de mecanismos confiáveis e ágeis de avaliação dos mesmos. A grande preocupação neste pólo de tensão regulatória é, por meio da 
legislação e acompanhamento, garantir a qualidade dos mesmos e sua conseqüente legitimação junto à sociedade como alternativa educacional eficaz.

No caso das políticas voltadas para as IES há um dilema típico das políticas públicas em geral. Quanto mais abrangentes e menos regulatórias as políticas públicas, maior o risco de inclusão em seus programas daqueles que delas deveriam ficar fora. Em outras palavras, quanto menos regulatória a legislação, maior o risco de oferta de cursos com baixa efetividade educacional. Por outro lado, quanto maior o nível de regulação, menores os espaços para inovação em termos de cursos nas suas características mais gerais, ou seja, menor a capacidade de boa resposta das IES às demandas inovadoras do mercado de trabalho formado pelo $\mathrm{SNI}$ e pelo mercado em geral.

\section{A constituição de um SNI educacional e um lugar para as IES}

No tocante à montagem e funcionamento dos SNI nacionais, é interessante ir além de pensar simplesmente na inserção de todo o sistema educacional no mesmo. $\mathrm{Na}$ verdade, a dinâmica das EBCs exige a constituição de um subsistema de inovação na própria área educacional. Conceber o todo deste subsistema em termos do ensino básico, médio, superior, e neste, as universidades e as atividades de pesquisa e extensão é tarefa para um trabalho muito mais extenso e aprofundado que este. Entretanto, apenas para exercício, vale projetar que especialmente para o setor das IES - por definição, flexível, contextualizado e interdisciplinar - a noção de um sistema de inovação próprio - uma rede - é bastante adequada para lidar com as tensões existentes entre os atores nela envolvidos. Considerar as IES como parte de um sistema de inovação educacional retira-as da posição de apenas responder às demandas existentes na sociedade e as coloca na condição de, agindo interativamente com os demais atores pertencentes a este sistema, inovar na oferta de oportunidades de formação profissional.

\section{Considerações finais}

A literatura revisada a respeito da EBC ressalta a importância dos sistemas educacionais no desenvolvimento social e econômico e na inovação tecnológica, crucial para o sistema produtivo. Contextualizar o Brasil neste cenário salienta, por um lado, suas deficiências estruturais já crônicas, e, por outro lado, seus esforços de regulamentação, reformulação e expansão do setor educacional. Contudo, por mais valiosos que sejam os esforços públicos para desempenhar seu papel fomentador de produção e utilização do conhecimento por meio de planejamento e implementação, os resultados podem ser comprometidos. As ameaças podem ser a falta ou deficiência de mecanismos de avaliação e de acompanhamento dos resultados e impactos nos agentes envolvidos. Com isto, o risco é não saber de que forma as metas estabelecidas estão sendo alcançadas, ou mesmo não saber se elas sequer foram efetivadas. Uma agenda de pesquisas sobre o que e quem avaliar neste processo pode retomar o rumo de mecanismos de operacionalização, permitir revisar suas finalidades e corrigir eventuais distorções. 
No caso da educação profissional brasileira e, em específico, na modalidade de cursos tecnológicos, diversas ações públicas foram implementadas na última década. A expansão dos cursos aponta para a legitimidade que eles adquirem na sociedade, embora ainda não seja claro de que forma ela tem sido absorvida no âmbito empresarial. Tais mudanças trouxeram certamente impactos para todos os stakeholders, sejam quantitativas (como o aumento do número de concluintes de curso superior), ou sejam qualitativas (como a qualificação da força de trabalho no mercado). Trata-se de um poderoso mecanismo dentro do contexto das EBC's, porém que precisa ser devidamente utilizado. Estas mudanças criam tensões e dúvidas, mas também aprendizado e competência, que precisa ser institucionalizado nas organizações reguladoras a fim de que não se perca a experiência acumulada. Para avaliar estes resultados é importante a discussão e análise das políticas públicas definidas com vistas às suas possibilidades de melhoria.

Por fim, vale salientar que os resultados das políticas no âmbito educacional geram resultados de médio e longo prazos, e, por isso, requerem acompanhamento sistemático e contínuo. $\bigcirc$ Brasil parece despertar para esta realidade. Mas apenas desperta. Carece ainda de avançar na criação e melhoria de uso dos seus indicadores a fim de incrementar seus resultados. Muitos desafios ainda permanecem para que a educação seja um pilar da EBC. Futuras pesquisas neste sentido podem auxiliar ao investigar IES, agências de fomento, organizações públicas de regulamentação, ou mesmo a sociedade na forma de pesquisa com discentes e egressos. 


\section{Referências}

ABRANCHES, S. H. H. O leviatã anêmico: dilemas presentes e futuros da política social. Planejamento e políticas públicas, Brasília, DF, n. 1, p. 7-32, 1989.

ANET. Educação profissional de nível tecnológico. [S. I.: s. n.], 2003.

BENGTSSON, J. Educação para a economia do conhecimento: novos desafios. In: VELLOSO, J. P. R. O Brasil e a economia do conhecimento. Rio de Janeiro: José Olympio, 2002.

BRASIL. Constituição (1988). Constituição da República Federativa do Brasil. Diário Oficial [da República Federativa do Brasil], Brasília, DF, 5 out. 1988.

Decreto $n^{\circ}$. 2.208, de 17 de abril de 1997. Regulamenta o $\S 2^{\circ}$ do art.

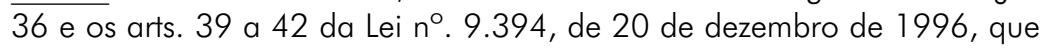
estabelece as diretrizes e bases da educação nacional. Diário Oficial [da República Federativa do Brasil], Brasília, DF, 18 abr. 1997a.

Decreto $n^{\circ}$. 5.154, de 23 de julho de 2004. Regulamenta o $\S 2^{\circ}$ do art. 36 e os arts. 39 a 41 da Lei $n^{\circ}$. 9.394, de 20 de dezembro de 1996, que estabelece as diretrizes e bases da educação nacional e dá outras providências. Diário Oficial [da República Federativa do Brasil], Brasília, DF, 24 jul. 2004a.

- Decreto n. 5.159, de 28 de julho de 2004. Aprova a Estrutura Regimental e o quadro Demonstrativo dos Cargos em Comissão e das Funções Gratificadas do Ministério da Educação. Diário Oficial [da República Federativa do Brasil], Brasília, DF, 29 jul. 2004b.

. Lei $n^{\circ}$. 4.024, de 20 de dezembro de 1961. Fixa as diretrizes e bases da educação nacional. Diário Oficial [da República Federativa do Brasil], Brasília, DF, 27 dez. 1961 e retificada em 28 dez. 1961.

. Lei $n^{\circ}$ 9.394, de 20 de dezembro de 1996. Estabelece as diretrizes e bases da educação nacional. Diário Oficial [da República Federativa do Brasil], Brasília, DF, 23 de dez. 1996. Seção 1, p. 27.839.

. Lei $n^{\circ}$. 9.649, de 27 de maio de 1998. Dispõe sobre a organização da Presidência da República e dos Ministérios, e dá outras providências. Diário Oficial [da República Federativa do Brasil], Brasília, DF, 28 maio 1998.

. Lei $n^{\circ}$. 10.861, de 14 de abril de 2004. Institui o Sistema Nacional de Avaliação da Educação Superior - SINAES e dá outras providências. Diário Oficial [da República Federativa do Brasil], Brasília, DF, 15 abr. 2004c. BRASIL. Ministério da Educação. Portaria n ${ }^{\circ}$ 1.005, de 10 de setembro de 1997. Institui no âmbito da Secretaria de Educação Média e Tecnológica - SEMTEC, a Unidade de Coordenação do Programa - UCP. Brasília, DF, 1997b. Disponível em: <portal.mec.gov.br/setec/arquivos/pdf/legisla04.pdf ->. Acesso em: 8 maio 2008. 
BRASIL. Ministério da Educação. Portaria n 1.647 , de 25 de novembro de 1999. Dispõe sobre o credenciamento de centros de educação tecnológica e a autorização de cursos de nível tecnológico da educação profissional. Brasília, DF, 1999. Disponível em: <http://portal.mec.gov.br/setec/arquivos/pdf/ PMEC1647_99.pdf>. Acesso em: 8 maio 2008.

. Portaria $n^{\circ}$. 2.051, 9 de julho de 2004. Regulamenta os procedimentos de avaliação do Sistema Nacional de Avaliação da Educação Superior (SINAES), instituído na Lei no 10.861, de 14 de abril de 2004. Brasília, DF, 2004d. Disponível em: <portal.mec.gov.br/conaes/arquivos/pdf/portaria_2051.pdf ->. Acesso em: 8 maio 2008.

. Portaria $n^{\circ} .3 .621$, de 4 de dezembro de 2003. Dispõe sobre a criação, atribuições e funcionamento do Fórum Nacional de Educação Profissional e Tecnológica. Diário Oficial [da República Federativa do Brasil], Brasília, DF, 5 dez. $2003 a$.

- Ministério da Educação. Secretaria de Educação Profissional e Tecnológica. Pacto pela valorização da educação profissional e tecnológica: por uma profissionalização sustentável: proposta de agenda mínima pactuada entre MEC/ SETEC, CENCEFET, CONDAF, CONDETUF, SINASEFE. $2003 \mathrm{~b}$.

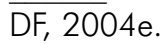

. Políticas públicas para a educação profissional e tecnológica. Brasília, - Subsídios para a discussão de proposta de Anteprojeto de Lei Orgânica da Educação Profissional e Tecnológica. Brasília, DF, 2003c.

Ministério da Educação e do Desporto. Portaria $n^{\circ}$. 646, de 14 de maio de 1997. Regulamenta a implantação do disposto nos artigos 39 a 42 da Lei Federal $n^{\circ}$. 394/96 e no Decreto Federal n 2.208/97 e dá outras providências (trata da rede federal de educação tecnológica). Brasília, DF, 1997c. Disponível em: <portal.mec.gov.br/setec/arquivos/pdf/PMEC646_97.pdf ->. Acesso em: 8 maio 2008.

. Ministério da Educação e do Desporto. Ministério do Trabalho. Portaria $\overline{n^{\circ} .1 .018, ~ d e ~} 11$ de setembro de 1997. Cria o Conselho Diretor do Programa de Reforma da Educação Profissional - PROEP. Brasília, DF, 1997d. Disponível em: <www8.pr.gov.br/portals/portal/institucional/dep/ep_port1018.pdf ->. Acesso em: 8 maio 2008.

CASTElLS, M. A sociedade em rede. São Paulo: Paz e Terra, 1999. (A era da informação: economia, sociedade e cultura; v. 1).

CASTRO, C. M. O despertar do gigante: com menos ufanismo e mais direção, a educação brasileira acorda. Belo Horizonte: MG-Ed. Universidade, 2003. 
CASTRO, M. H. G. Um sistema de educação para atender à economia do conhecimento. In: VELLOSO, J. P. R. O Brasil e a economia do conhecimento. Rio de Janeiro: José Olympio, 2002.

CONSELHO NACIONAL DE EDUCAÇÃO. Câmara de Educação Superior. Parecer CNE/CES 436, de 2 de abril de 2001. Cursos superiores de tecnologia: formação de tecnólogos. Diário Oficial [da República Federativa do Brasil], Brasília, DF, 6 abr. 2001. Seção 1E, p. 67.

Conselho Pleno. Parecer CNE/CP 29, de 3 de dezembro 2002. Diretrizes Curriculares Nacionais Gerais para a educação profissional de nível tecnológico. Diário Oficial [da República Federativa do Brasil], Brasília, DF, 13 dez. 2002. Seção 1, p. 162.

CURSOS tecnológicos em expansão. Paraná- online, Curitiba, fev. 2005. Disponível em: <http://www.parana-online.com.br/pron.php>. Acesso em: 12 fev. 2004.

DAHLMAN, C.J. A Economia do conhecimento: implicações para o Brasil. In: VELLOSO, J.P.R. O Brasil e a economia do conhecimento. Rio de Janeiro: José Olympio, 2002.

FLEURY, A. C. C.; FLEURY, M. T. L. Estratégias empresariais e formação de competências: um quebra cabeça caleidoscópico da indústria brasileira. 2. ed. São Paulo: Atlas, 2004.

FORAY, D.; LUNDVALL, B. A. The knowledge-based economy: from the economics of knowledge to the learning economy. In: OECD. Employment and growth in the knowledge-based economy. Paris: OECD, 1996.

GIDDENS, A. A terceira via. Rio de Janeiro: Record, 1999.

HENRIQUES, P. T. C. Changing of paradigm: developing a contemporary strategy for technological education in Brazil. Oklahoma, 1999. Tese (Doutorado em Educação) - Oklahoma State University, Oklahoma, 1999.

LENHARI, L. C.; QUADROS, R. Recursos humanos nas economias baseadas no conhecimento. Revista Inteligência Empresarial, Rio de Janeiro, n. 12, p. 30-38, jul. 2002.

LUNDVALL, B. Políticas de innovación en la economía de aprendizaje. Revista Latinoamericana de Estudios del Trabajo, Buenos Aires, año 8, n. 16, 2003.

OECD. The knowledge-based economy. Paris, 1996.

PAULA, J. A.; CERQUEIRA, H. E. G.; ALBUQUERQUE, E. M. Trabalho e conhecimento: lições de clássicos para a análise do capitalismo contemporâneo. Estudos Econômicos, São Paulo, v. 30, n. 3, p. 419-445, jul./set. 2000. 
QUINN, J. B.; ANDERSON P.; FINKELSTEIN, S. Gerenciando o intelecto profissional: extraindo o máximo dos melhores. In: GESTÃO do conhecimento. Rio de Janeiro: Campus, 2000. (Coleção Harvard Business Review).

SEMINÁRIO NACIONAL DE EDUCAÇÃO PROFISSIONAL: concepções, experiências, problemas e propostas, 2003, Brasília. Documento base. Brasília, DF: MEC, SEMTEC, PROEP, 2003a.

SEMINÁRIO NACIONAL DE EDUCAÇÃO PROFISSIONAL: concepções, experiências, problemas e propostas, 2003, Brasília. Relatório final: o grande coletivo, seus consensos e dissonâncias. Brasília, DF: MEC, SEMTEC, PROEP, $2003 b$.

SOUZA, P. R. A revolução gerenciada: educação no Brasil, 1995-2002. São Paulo: Prentice Hall, 2005.

STERN, D. Human resource development in the knowledge-based economy: roles of firms, schools, and governments. In: OECD. Employment and growth in the knowledge-based economy. Paris, 1996.

TAKAHASHI, A. R. W. Contexto ambiental, esquemas interpretativos e estratégias de ação: estudo comparativo de casos em duas organizações escolares de ensino público de Curitiba, PR. 2001. Dissertação (Mestrado em Administração) - Centro de Pesquisa e Pós-Graduação em Administração, Universidade Federal do Paraná, Curitiba, 2001.

TAKAHASHI, A. R. W.; CASTOR, B. V. J. Globalização: produção de conhecimento, tecnologia de informação e competitividade internacional - o caso do Brasil. In: ENCONTRO ANUAL DA ANPAD, 24., 2000, Florianópolis. Anais... Florianópolis: ANPAD, 2000. 1 CD-ROM.

ZONTA, N. O perfil de quem decide ser tecnólogo. O Estado de São Paulo, São Paulo, 28 out. 2005.

Recebido em: 20/12/2007

Aceito para publicação em: 15/04/2008 